\title{
Application of Midfrequency Electrostimulation Therapeutic Apparatus in Dysphasia
}

\author{
Yayun Yan \\ Neurology Department of China-Japan Union Hospital \\ Jilin University \\ Changchun City, China \\ cjj@jlu.edu.cn
}

Xiaoyang Liu

Neurology Department of China-Japan Union Hospital

Jilin University

Changchun City, China

cjj@jlu.edu.cn

Abstract: Objective: Discuss application of midfrequency electrostimulation therapeutic apparatus in dysphasia. Method: research a kind of new electrostimulation therapeutic apparatus and clinical effect which is researched and developed based on generation mechanism of dysphagia and carries out treatment according to different prescriptions. Result: 1. Clinical efficacy: total efficiency of evaluation methods of two swallow capacity is $100.00 \%$; the total effectual rate is $\mathbf{6 0 . 0 0 \%}$ (criterion for curative effect of Watian swallow capacity) and $63.33 \%$ (criterion for curative effect of dysphagia apgar scale) respectively. 2 . Observation of untoward effect: patients do not have uncomfortable and untoward effects obviously. Conclusion: a kind of new percutaneous electrostimulation therapeutic apparatus_midfrequency electrostimulation swallow therapeutic apparatus is a new recommendable electrostimulation therapeutic measure with high security and good curative effect which can conduct individualized treatment according to different prescriptions of different diseases (treatment time, base-segment frequency, interval and selection of wave shape) and reduce

\author{
Wei Quan \\ Neurology Department of China-Japan Union Hospital \\ Jilin University \\ Changchun City, China \\ cjj@jlu.edu.cn \\ Jiajun Chen* \\ Neurology Department of China-Japan Union Hospital \\ Jilin University \\ Changchun City, China \\ *Corresponding author: Jiajun Chen, cjj@jlu.edu.cn \\ unnecessary toxic sideeffect.
}

Keywords-Midfrequency Electrostimulation;

Dysphagia; Cerebral Apoplexy; Therapeutic

apparatus; Therapeutic measure

\section{INTRODUCTION}

In recent years, occurring rate of dysphagia has been increasing yearly 【1-4】, which means that food cannot be digested from mouth to stomach due to functional damages to medulla oblongata or throat due to age or other reasons. Although researches have been conducted on percutaneous electrostimulation of swallow, there have been no final conclusion yet【5】. At present, researches 【 6-8】 mainly concentrate on influences of electrostimulation upon dysphagia. In the thesis, a new electrostimulation therapeutic apparatus-ZTY-II midfrequency electrostimulation therapeutic apparatus with dysfunction is introduced.

Brief Introduction of ZTY-II Swallow Therapeutic Apparatus

ZTY-II swallow therapeutic apparatus (hereinafter referred to as therapeutic apparatus) is a kind of physical recovery therapeutic apparatus delicately design according to clinical curative features of dysphagia by virtue of advantages of similar products at home and 
abroad, which is mainly used to nervous dysphagia caused by mechanical injuries.

Composition, properties and technical parameters of product ZTY-II swallow therapeutic apparatus mainly consists of the host machine, the electrode wire, the absorption electrode, the fixed bind and the power line.

Main parameters of ZTY-II swallow therapeutic apparatus LF carrier frequency: $1 \mathrm{KHz}, 2 \mathrm{KHz}, 3 \mathrm{KHz}$, $4 \mathrm{KHz}, 5 \mathrm{KHz}$, error range: $\pm 10 \%$. LF modulation frequency: $0.5-150 \mathrm{~Hz}$, error range: $\pm 10 \%$.

Modulation wave shape: square wave, triangular wave, exponential wave, sine wave Pulse width: the pulse width can be seen in Table 1; the load is $500 \Omega( \pm 10 \%)$; error range: $\pm 10 \%$.

TABLE I. PULSE WIDTHS OF FREQUENCIES WHEN THE LOAD IS $500 \Omega( \pm 10 \%)$

\begin{tabular}{|c|c|c|c|c|c|}
\hline Frequency & $1 \mathrm{kHz}$ & $2 \mathrm{kHz}$ & $3 \mathrm{kHz}$ & $4 \mathrm{kHz}$ & $5 \mathrm{kHz}$ \\
\hline $\begin{array}{c}\text { Pulse } \\
\text { width }\end{array}$ & $360 \mu \mathrm{s}$ & $150 \mu \mathrm{s}$ & $100 \mu \mathrm{s}$ & $80 \mu \mathrm{s}$ & $70 \mu \mathrm{s}$ \\
\hline
\end{tabular}

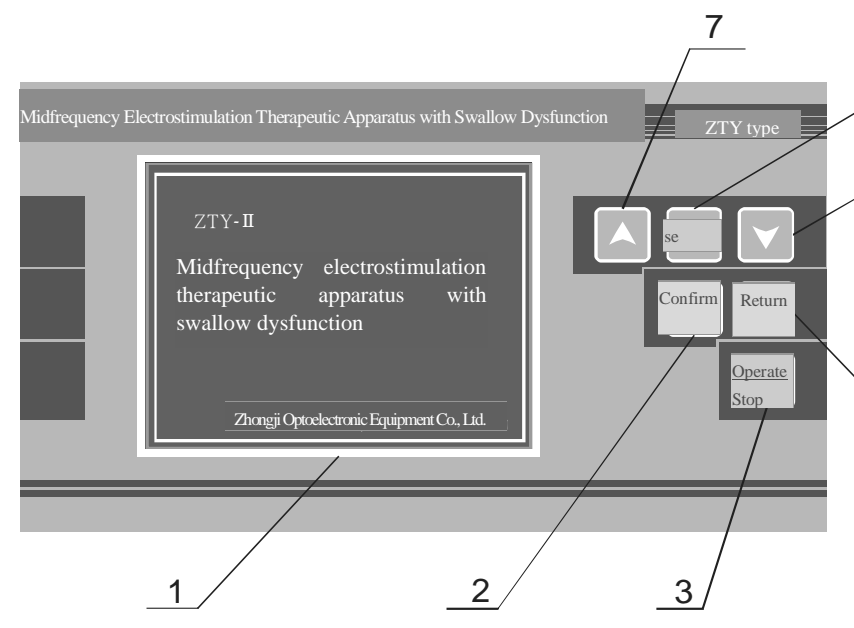

Figure1. Control panel

The control panel of the therapeutic apparatus.The control panel of the swallow therapeutic apparatus is described in Fig.1; it is a microcomputer control system with clear identification and can be operated simply.

(1)LCD (2) Confirm button: Press Confirm and enter into the submenu or the working interface after choosing corresponding disease. (3) Operate/Stop button: press the button and switch working condition of the therapeutic apparatus. (4) Return button: return to last menu. (5), (7)
“ " " ": adjust parameters up and down. (6) Press Choose to choose parameters needing adjusting after entering into the adjusting interface of working parameters.

\section{APPLICATION METHOD}

ZTY- II swallow therapeutic apparatus is controlled by microcomputer system and displayed by large screen LCD and Chinese menu with friendly prompt interface and preset curative prescription, which can expand variety according to clinical demands and is convenient for choosing treatment. Each curative scheme correspond to an interface; each interface has corresponding adjustable parameters; these parameters can be divided into: 1. treatment time: setting of working hour of the therapeutic apparatus; 2 . base frequency: namely midfrequency, frequency of the carrier signal of the therapeutic apparatus; 3. modulation frequency: modulation wave frequency generated from modulation carrier signal; 4. selection of wave shape: wave shape generated from modulation carrier signal; 5. interval: interval of two modulation waves; 6. output strength: grade instruction of current and voltage parameters exported from the therapeutic apparatus. There are many Qathogenesis for clinical dysphagia; the therapeutic 5pparatus conducts individualized treatment by different prescriptions and different causes and through adjusting parameters and can conduct user-defined setting according to clinical experience of doctors.

\section{II. Result (AsSESSMENT OF CLINICAL EFFiCACY)}

China-Japan Union Hospital of Jilin University and Integrated Chinese and Western Medicine Hospital of Jilin Province have conducted clinical observation to such swallow therapeutic apparatus and figure out the following results: 1 . clinical efficacy: conclusions of evaluation methods of two swallow capacities (evaluation method of Watian swallow capacity and evaluation method of dysphagia apgar scale can be seen in the addendum) are approximate and the total efficiency is $100.00 \%$, the total effectual rate is $60.00 \%$ (criterion for curative effect of Watian swallow capacity) and $63.33 \%$ (criterion for curative effect of dysphagia apgar scale) respectively. According to statistics treatment, comparison between criterion for curative effect of 
Watian swallow capacity and curative effect of the data group is: $\mathrm{X} 2=4.702, \mathrm{P}>0.05$; the difference between curative effects of two groups does not have statistics meaning; comparison between criterion for curative effect of dysphagia apgar scale and the data group is: $\mathrm{X} 2=4.309$, $\mathrm{P}>0.05$; the difference between curative effects of two groups does not have statistics meaning. 2. observation of properties of the swallow therapeutic apparatus: the output standard of current is in accordance with the nominal value; the electrode should be pasted comfortably; there is no misoperation during the treatment; the alarm prompt function is normal and there is no electric potential safety hazard. 3. observation of untoward effect: there is no obvious and untoward effect in patients, indicating that the apparatus can be used safely and reliably under regulated operation method.

TABLE II. ANALYSIS OF CLINICAL EFFICACY

\begin{tabular}{|c|c|c|c|}
\hline & Excellent & Effective & Ineffective \\
\hline $\begin{array}{lr}\text { Criterion } & \text { for } \\
\text { curative effect of } \\
\text { Watian } & \text { swallow } \\
\text { capacity } & \end{array}$ & $\begin{array}{c}18 \\
(60.00 \%)\end{array}$ & $\begin{array}{c}12 \\
(40.00 \%)\end{array}$ & 0 \\
\hline $\begin{array}{l}\text { Criterion for } \\
\text { curative effect on } \\
\text { the apgar scale of } \\
\text { dysphagia }\end{array}$ & $\begin{array}{c}19 \\
(63.33 \%)\end{array}$ & $\begin{array}{c}11 \\
(36.67 \%)\end{array}$ & 0 \\
\hline $\begin{array}{l}\text { References }^{[9]} \\
\text { Criterion for } \\
\text { curative effect }\end{array}$ & $\begin{array}{c}16 \\
(64.00 \%)\end{array}$ & $\begin{array}{c}6 \\
(24.00 \%)\end{array}$ & $\begin{array}{c}3 \\
(12.00 \%)\end{array}$ \\
\hline
\end{tabular}

\section{DISCUSSION}

Dysphagia is a kind of common clinical symptom. Generally speaking, generation mechanism of swallow is that after surrounding or central nerves of the supporting the swallow muscle are damaged, movement of the tongue is limited; pressure in the paralysis mouth of the soft palate and the pharynx cannot be raised fully; food cannot move from the mouth to the pharyngeal and the esophagus; the process is extended obviously; the retention is increased, which would lead to suffocation and aspiration easily[10].

Midfrequency electrotherapy is a mature technique of physiotherapy and has been extensively applied. Midfrequency electric technology is a new science with biology, physics and clinical medicine as a whole.

Modulation midfrequency technique controlled by computer is applied by the product; its functional features and curative effects to human body take on as follows:

1. Modulation midfrequency electricity has midfrequency electric elements, low impedance and deep function; it can apply strong current, has no electrolytic action and no stimulation to skin and can bring special physiological and curative functions of midfrequency current into full play.

2. Modulation midfrequency electricity has LF electric elements and its features, which can bring physiological and curative functions of low frequency into play.

3. Wave shape, range and frequency of modulation midfrequency electricity change unceasingly so that human body cannot adapt to it easily.

4. Adjust the modulation factor of modulation midfrequency electricity; adjustment of low-frequency element and amplitude is to change strength of stimulation so as to adapt to different curative demands.

5. Modulation midfrequency electricity can promote blood circulation obviously.

6.Exercise functions of muscles.

7. Functions of reflection of ganglions and vegetative nervous and adjustment of vegetative nerves.

\section{CONCLUSION}

A kind of new percutaneous electrostimulation therapeutic apparatus - midfrequency electrostimulation swallow therapeutic apparatus is introduced in the thesis, which breaks the single curative mode of dysphagia in the past and conducts individualized treatment according to different prescriptions according to different diseases (treatment time, base frequency, interval and selection of wave shape), reducing unnecessary toxic sideeffect.

\section{REFERENCES}

[1] Blumenfeld L, LePage A, Leonard R, et al. Transcutaneous electrical stimulation versus traditional dysphagia therapy: A nonconcurrent cohort study [J]. Otolaryngology-Head and Neck Surgery, 2006, 135:754—757. 
[2] Huckabee ML, Lamvik K , Jones R . Pharyngeal mis-sequencing in dysphagia: Characteristics, rehabilitative response, and etiological speculation. Journal of the neurological sciences 2014 Aug; 343 (1-2 ):153-8.

[3] Brodsky MB , Gellar JE , Dinglas VD , Colantuoni E , Mendez-Tellez PA, Shanholtz C, Palmer JB , Needham DM . Duration of oral endotracheal intubation is associated with dysphagia symptoms in acute lung injury patients. Journal of critical care 2014 Aug; 29 (4 ):574-9.

[4] van der Vlugt M , Boone J , Ponsioen CY . Acute Dysphagia: don't wait and see. Gastroenterology 2014 Aug; 147 (2 ):281-2

[5] H. Taniguchi, S. Ootaki, Y. Kajii, Y. Yamada, and M. Inoue, "Relationship between muscular atrophy of the tongue and impairment of bolus transport during swallowing in patients with amyotrophic lateral sclerosis", The Journal of Japanese Society of Stomatognathic Function, vol. 15, no. 1, pp. 30-37, 2008.
[6] Kong Yuenan and Sun Yang. Research on Curative Effect of Dysphagia after Treating Cerebral Apoplexy by Electrostimulation Therapy [J]. Neurologic Disease and Mental Health, 2008, 8(2): $410-412$.

[7] Ludlow CL, Humbert IJ, Saxon KG, et al. Effects of surface stimula tion both at rest and during swallowing in chronic pharyngeal dysphagia [J]. Dysphagia, 2007, 22(1): 1-10.

[8] M. Saito, "The study of dysphagia (in Japanese)," Journal of Cookery Science of Japan, vol. 43, no. 5, pp. 281-285, 2010.

[9] Steele CM. Electrical stimulation of the pharyngeal swallow: Does the evidence support application in clinical practice [J] Speech-Lang Pathol Audiol, 2004, 28(2):77—83.

[10] Crary MA , Carnaby GD , LaGorio LA , Carvajal PJ . Functional and physiological outcomes from an exercise-based dysphagia therapy: a pilot investigation of the McNeill Dysphagia Therapy Program. Archives of physical medicine and rehabilitation 2012 Jul; 93 (7 ):1173-8. 